\title{
Evaluation of General Practice Pharmacists: Study Protocol to Assess Interprofessional Collaboration and Team Effectiveness
}

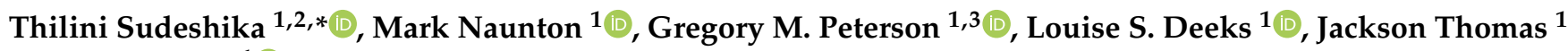 \\ and Sam Kosari ${ }^{1}$ (D) \\ 1 Discipline of Pharmacy, Faculty of Health, University of Canberra, Bruce ACT 2617, Australia; \\ Mark.Naunton@canberra.edu.au (M.N.); g.peterson@utas.edu.au (G.M.P.); \\ louise.deeks@canberra.edu.au (L.S.D.); jackson.thomas@canberra.edu.au (J.T.); \\ sam.kosari@canberra.edu.au (S.K.) \\ 2 Department of Pharmacy, Faculty of Allied Health Sciences, University of Peradeniya, \\ Peradeniya 20400, Sri Lanka \\ 3 School of Pharmacy and Pharmacology, University of Tasmania, Hobart TAS 7005, Australia \\ * Correspondence: thilini.salpahewage@canberra.edu.au
}

check for updates

Citation: Sudeshika, T.; Naunton, M.; Peterson, G.M.; Deeks, L.S.; Thomas,

J.; Kosari, S. Evaluation of General Practice Pharmacists: Study Protocol to Assess Interprofessional

Collaboration and Team Effectiveness. Int. J. Environ. Res. Public Health 2021, 18, 966. https://doi.org/10.3390/ ijerph18030966

Received: 5 December 2020

Accepted: 20 January 2021

Published: 22 January 2021

Publisher's Note: MDPI stays neutral with regard to jurisdictional claims in published maps and institutional affiliations.

Copyright: (c) 2021 by the authors. Licensee MDPI, Basel, Switzerland This article is an open access article distributed under the terms and conditions of the Creative Commons Attribution (CC BY) license (https:// creativecommons.org/licenses/by/ $4.0 /)$

\begin{abstract}
The inclusion of pharmacists into general practices has expanded in Australia. However, there is a paucity of research examining interprofessional collaboration and team effectiveness after including a pharmacist into the general practice team in primary or community care. This is a protocol for a cross-national comparative mixed-methods study to (i) investigate interprofessional collaboration and team effectiveness within the general practice team after employing pharmacists in general practices in the Australian Capital Territory (ACT) and (ii) to compare interprofessional collaboration and team effectiveness of pharmacists in general practice across Australia with international sites. The first objective will be addressed through a multiphase sequential explanatory mixed-method design, using surveys and semi-structured interviews. The study will recruit general practice pharmacists, general practitioners, and other health professionals from eight general practices in the ACT. Quantitative and qualitative results will be merged during interpretation to provide complementary perspectives of interprofessional collaboration. Secondly, a quantitative descriptive design will compare findings on interprofessional collaboration (professional interactions, relationship initiation, exchange characteristics, and commitment to collaboration) and team effectiveness of general practice pharmacists in Australia with international sites from Canada and the United Kingdom. The results of the study will be used to provide recommendations on how to best implement the role of general practice pharmacists across Australia.
\end{abstract}

Keywords: interprofessional collaboration; general practice; general practice pharmacists; team effectiveness; inclusion; evaluation

\section{Introduction}

In Australia, general practice clinics are often the frontline primary health care service, with almost $90 \%$ of the population visiting a general medical practitioner at least once each year [1]. There is expected to be a $37.5 \%$ increase in the demand for general practice services between 2019 and 2030 [2]. The main factors driving this demand are the ageing population and the increasing impact of chronic diseases [2-5]. Higher demands for general practice services can cause excessive workload and stress for general practitioners, which may lead to lower quality of patient care [6,7]. The allocation of appropriate service provision to other primary health-care professionals can assist in addressing health system challenges due to complex patient profiles, patient expectations, and expanded demands $[1,8]$.

Medication-related problems, including nonadherence, drug interactions, and adverse events, are gradually increasing in primary care [9-13]. In 2016-2017, it was reported that 250,000 hospital admissions and 400,000 presentations to emergency departments in 
Australia annually result from medication-related problems, and half of these hospital presentations are considered preventable [14,15]. Unplanned hospital admissions due to medication misadventure were estimated to have cost $\$ 1.4$ billion to the Australian health care system in 2016-2017 [15].

Medication-related problems can occur due to poor communication and collaboration between community pharmacists and general practitioners [16]. The main barriers to communication include separate locations, limited face-to-face communication, and lack of routine access to patients' medical records [17]. The inclusion of pharmacists in general practice teams is likely to address these barriers to collaboration and communication between pharmacists and general practitioners [18], and consequently may reduce adverse medication outcomes in primary care [19]. Pharmacists in general practice can identify and prevent medication-related problems [20], support general practitioners to improve the quality use of medicines, minimise the risks associated with medications, and improve patients' health outcomes [19].

The integration of pharmacists into general practices has been studied in several countries, including Canada, United States of America (USA), United Kingdom (UK), Australia, Netherlands, and Ireland [19-25]. The National Health Service England (NHSE) launched the Clinical Pharmacists in General Practice model in 2015 to address the general practitioner workforce crisis [23]. Clinical pharmacists are employed to work as part of the general practice team to improve patient care and consult with patients directly. This includes providing extra help to manage chronic health conditions, education to those on multiple medicines, and better access to health assessments [26]. There are currently over 1000 full-time equivalent general practice pharmacists working across the UK, with a 38\% increase of pharmacists in general practices year-on-year [27].

A large-scale project titled "Integrating Family Medicine and Pharmacy to Advance Primary Care Therapeutics (IMPACT)" has investigated the integration of pharmacists into family health teams since 2004-2006 in Ontario, Canada [24]. The IMPACT project aimed to improve collaborative practice between pharmacists, family physicians, and allied health professionals in managing medication therapy [24]. In this project, non-dispensing pharmacists provided patient medication interviews and assessments, medication management enhancement, patient education, and drug information [24,28]. Studies from Canada have reported the positive patient-centred activities of pharmacists as a part of the primary care team in providing integrated care $[28,29]$.

In Australia, the pharmacist's clinical role is generally limited to community pharmacies, hospitals, and consulting at aged-care facilities or when performing home medicines reviews [30]. Even though having clinical pharmacists working in general practice was first trialled in two projects in the early 2000s [31], this model has slowly expanded since around 2012. The concept of pharmacists working in general practice was supported by the Australian Medical Association, Pharmaceutical Society of Australia, and by various Primary Health Networks [32]. Limited number of pharmacists have been employed in general practice to provide various non-dispensing services, including patient education, medication reviews and other medication management, clinical audits, and administrative work [33]. Australian studies have indicated that integration of pharmacists into general practice is likely to reduce fragmentation of patient care and medication misadventure [34,35].

Interprofessional collaboration in healthcare is defined as multiple health professionals from diverse disciplines working together with patients, families, caregivers, and communities to deliver the highest quality of care [36]. A formal care team of health professionals is characterised by collaborative practice agreements between professionals, and responsibilities are distributed among the team members under such agreements [37]. According to the good pharmacy practice guidelines developed by the International Pharmaceutical Federation and the World Health Organisation, multidisciplinary collaboration among health-care professionals has been emphasized as a key factor to improve patient safety [38]. Further, guidelines suggested that pharmacists should collaborate with other health care professionals to improve health outcomes [38]. 
Interprofessional collaboration not only improves patient care and outcomes; it is required to improve job satisfaction, and reduce medication-related problems, inefficiencies, and health-care costs $[20,39,40]$. Where there is lack of collaboration and communication in health care delivery, poor patient outcomes, such as hospital re-admissions and medicationrelated problems, are common [41,42]. In addition, the absence of collaboration can cause ineffective teamwork, poor team management, and fragmented care $[43,44]$. However, successful collaborative care is not easy to achieve and can be affected by problems linked to uncertainties over authority, inadequate understanding of others' tasks and liabilities, and professional boundary friction when delivering patient care [40].

Team effectiveness in health care is defined as a team's capacity to achieve its goals and objectives to optimise patient care [45]. Team effectiveness is a combination of team processes, including shared understanding of goals, role specification, conflict resolution, information exchange, and leadership [46]. Team effectiveness is essential for patient safety when patients are looked after by more than one health professional; however, it can be affected by instability of the teams, the culture of the workplace, and inability to resolve conflicts [46-48].

The Australian general practice team commonly includes multiple health professionals. Coordination and collaboration between the team of professionals, including general practitioners, psychologists, dieticians, pathologists, physiotherapists, nurse practitioners, and nurses, is essential to deliver effective patient care $[49,50]$. Similarly, general practices in the UK and Canada provide integrated care for their patients: they include general practitioners/family physicians, nurses or nurse practitioners, and at least one other allied health professional such as dietician or psychologist [51,52]. They have included pharmacists into their teams to work directly with general practitioners/physicians, other health care professionals, and patients with the aim of optimizing patients' medication regimens, health outcomes, and coordination of care [24,26]. The inclusion of pharmacists into general practice is relatively new to Australian general practices. Therefore, interprofessional collaboration and team-effectiveness within a large team of health professionals may be challenging when a practice pharmacist is being included into the established teams in general practices. Prior studies that investigated general practice pharmacists in Australia have reported stakeholders' perspectives on aspects of collaboration using a qualitative methodology $[18,53]$. However, there has been a paucity of research exploring how interprofessional collaboration develops between the general practice pharmacist and other health professionals in general practice, while the collaboration between general practitioners and community pharmacists and nurses/nurse practitioners has been relatively well investigated [54,55].

The aim of this study is to evaluate interprofessional collaboration and team effectiveness after the inclusion of pharmacists into the general practice team. This cross-national comparative mixed-method study has been designed comprising two parts, Part A and B.

\section{The Study}

\subsection{Study Instruments}

In this study, two surveys (as described below) will be utilized to assess interprofessional collaboration and team effectiveness. Semi-structured interviews will be utilized to describe participants' perception on how interprofessional collaboration developed among general practice team members.

\subsubsection{Collaborative Care Survey (CCS)}

The CCS was developed to assess professional interactions, exchange characteristics (relationship initiation, trustworthiness, and role specification), and commitment to collaboration (Additional file S1). The survey is adapted from validated instruments that assessed community pharmacist-general practitioner relationships [37,56,57]. Survey questions were modified to investigate practice pharmacists' relationships with general practitioners and allied health professionals. Questions in part 2 of CCS were formed 
by modifying the Frequency of Interprofessional Collaboration Instrument for Pharmacists (FICI-P), which is a 10-item unidimensional indicator that describes collaborative behaviour between community pharmacists and general practitioners in primary care [56]. The Pharmacist-Physician Collaborative Instrument (PPCI) was used to develop questions in part 3 of the CCS. The PPCI is a validated survey tool to identify physician-community pharmacist collaboration [57]. The PPCI includes seven themes covering collaborative working relationships: collaborative care, commitment, dependence symmetry, bidirectional communication, trust, initiating behaviour, and conflict resolution [56]. Professional interaction is measured on a 4-point scale, while exchange characteristics and commitment to collaboration are measured on 5-point Likert scales, indicating 1 (strongly disagree) to 5 (strongly agree).

The face validity of the CCS was reviewed by experts including one psychologist/ academic and nine pharmacists $(\mathrm{UK}=3$, Canada $=2$, Australia $=4$ ). Following the review by experts, several alterations were made to the questionnaire: for instance, by refining the clarity of contextual characteristics or amending the wording of Likert scale questions. Then questionnaires were modified by the researchers according to the recommendations made by the experts. The revised questionnaire (Additional file S1) was approved by the team of experts.

\subsubsection{Team Effectiveness Survey (TES)}

Questions to assess team effectiveness were adapted by the research team from a previously validated 31-item "Primary care team dynamics" survey [58]. The TES is a 24-item questionnaire that covers team processes and team performance domains: team effectiveness, shared understanding, processes for accountability, conflict resolution, acting and feeling like a team, and perceived team effectiveness (Additional file S2). The respondents will be asked to indicate the extent of agreement or disagreement for the statements on a 1 to 5-point Likert scale. The TES has similarities with CCS when assessing team processes (such as shared understanding, role specification, and team cohesion) while it differs from the CCS when assessing team performance domains (such as team effectiveness and perceived team effectiveness).

Following a pre-test of TES with experts and respondents $(n=8)$, the wording was amended according to their recommendations (Additional file S2). The final questionnaire was approved by the research team.

\subsubsection{Semi-Structured Interviews}

Semi-structured interviews will provide value in understanding the views of individuals on three main domains: role clarity, professional interaction (relationship, trust, communication, decision making), and collaboration (overall view, impact on team effectiveness, barriers, and facilitators) (Additional file S3). The interviews will gain participants' in-depth perceptions on how interprofessional collaboration developed among team members during the study period. The semi-structured interview guide was pre-tested with an experienced general practice pharmacist. The interview guide (Additional file S3: Domain 2) was amended based upon the comments.

\subsection{Part A-Interprofessional Collaboration and Team Effectiveness of General Practice Team in the Australian Capital Territory (ACT)}

\subsubsection{Aims}

This study aims to assess (i) changes in interprofessional collaboration over time, (ii) the facilitators/barriers for developing interprofessional collaboration, and (iii) the level of team effectiveness in general practice teams following the inclusion of pharmacists into general practice in the ACT. 


\subsubsection{Study Design}

This study comprises a multiphase sequential explanatory mixed-method design (QUAN-QUAL-QUAN), including surveys (collaborative care and team effectiveness surveys) and semi-structured interviews [59-61].

\subsubsection{Setting}

This study will be conducted in eight general practices in the ACT, Australia where the general practice pharmacist model is being trialled in a program conducted by the Capital Health Network (CHN), the ACT's primary health network [62].

\subsubsection{Intervention}

Pharmacists will be employed in eight general practices in the ACT on a part-time basis ( $15 \mathrm{~h}$ per week) for 18 months to provide non-dispensing services according to their own skillset and the local workplace needs determined by each practice. General practice pharmacists' non-dispensing services include providing patient education, medication reviews and other medication management services, medication safety initiatives such as clinical audits, and medication information to general practitioners. Following the inclusion of pharmacists into general practice teams, pharmacists will work with general practitioners and other health professionals to provide integrated care in these general practices.

\subsubsection{Participants and Recruitment}

The general practices eligible for the study will be identified and recruited by the CHN. These practices will be selected to reflect government-subsidised and private billing, and various locations in the ACT. General practice pharmacists will be recruited by the eligible general practices considering the local workplace needs determined by each practice.

General practice pharmacists, general practitioners, and other health professionals (may include nurses, nurse practitioners, psychologists, dieticians, and physiotherapists) $(n \approx 113)$ from eight general practices in the ACT, Australia will be invited to participate in surveys. For the qualitative component, all the general practice pharmacists $(n=8)$ and a purposeful sample of general practitioners and other allied health professionals in general practices $(n \approx 16)$ will be recruited $[63,64]$. Purposive sampling will be continued until the sample requirements are met by recruiting at least one pharmacist, one general practitioner, and one other health professional from each general practice. If it is believed that theoretical saturation is reached prior to full recruitment, then recruitment will discontinue $[65,66]$.

\subsubsection{Inclusion and Exclusion Criteria}

All potential participants who provide informed consent will be included in the study.

\subsubsection{Data Collection}

The CCS and TES will be administered to general practice pharmacists electronically (Qualtrics, Provo, UT). General practitioners and other health professionals will be provided with paper-based surveys. All the participants will be invited to complete the CCS at two time points, at baseline and 12 months [23]. The TES responses will be gathered only once from all the participants, at 12 months. The surveys will be opened for 8 weeks. The summary of the study sequence is shown in Table 1.

Qualitative data will be collected through semi-structured interviews, which will be conducted by one of the experienced researchers (L.S.D.) via telephone after obtaining the written consent at 12 months. Full interviews will be audiotaped, de-identified, and transcribed verbatim by an independent professional transcribing service [63,67]. Field notes will be used to supplement the audio and transcripts. 
Table 1. Summary of the study sequence.

\begin{tabular}{|c|c|c|}
\hline & Part A & Part B \\
\hline Design & $\begin{array}{c}\text { Multiphase sequential explanatory mixed } \\
\text { method }\end{array}$ & Cross-national quantitative descriptive \\
\hline Setting & $\begin{array}{l}\text { Eight general practices in the ACT where a } \\
\text { program nested with } \mathrm{CHN}\end{array}$ & $\begin{array}{c}\text { General practices in Australia, Canada, and } \\
\text { the UK }\end{array}$ \\
\hline Participants & $\begin{array}{l}\text { General practice pharmacists, general } \\
\text { practitioners and other health professionals } \\
\text { (may include nurses, nurse practitioners, } \\
\text { psychologists, dieticians, and } \\
\text { physiotherapists) }\end{array}$ & General practice pharmacists \\
\hline Sample size & $\begin{array}{l}\text { Pharmacists, GPs and other health } \\
\text { professionals from } 8 \text { general practices in the } \\
\text { ACT; target sample size } n=113 \text { for the } \\
\text { surveys, and } n=24 \text { for the interviews }\end{array}$ & $\begin{array}{l}\text { All general practice pharmacists; target } \\
\text { sample size } n=323 \text { from the UK, } n=249 \\
\text { from Canada, } n=63 \text { from Australia }\end{array}$ \\
\hline Inclusion and exclusion criteria & $\begin{array}{l}\text { Inclusion: Participants who provide } \\
\text { informed consent }\end{array}$ & $\begin{array}{l}\text { Inclusion: General practice pharmacists } \\
\text { who are currently working in general } \\
\text { practices in Australia, Canada, and the UK. } \\
\text { Exclusion: General practice pharmacists in } \\
\text { Part A of the study }\end{array}$ \\
\hline
\end{tabular}

Part-time pharmacists (15 hrs/week) will be employed into 8 general practices for 18 months to provide non-dispensing Intervention services such as providing patient education, medication management services, medication safety initiatives such as clinical

The general practice pharmacist model is already established as a routine practice audits, and medication information to general practitioners.

Collaborative care survey at baseline and 12 months, Team effectiveness survey at

12 months, and semi-structured interviews at 12 months
Changes in collaboration and team effectiveness, and identify barriers and

Outcomes facilitators of interprofessional collaboration after including general practice pharmacists
Collaborative care survey and Team effectiveness survey

Identify the level of interprofessional collaboration and team effectiveness, and the factors associated with collaboration at different study sites

CHN: Capital Health Network, ACT's primary health network, GP: General practitioner.

\subsubsection{Data Analysis}

Descriptive statistics will be used to summarise the demographic details of the participants. Reliability analysis (Cronbach's alpha test) will be conducted to assess the internal consistency of multiple items of CCS and TES [68].

Total CCS scores will be calculated for general practice pharmacists, general practitioners, and other health professionals [69]. Total scores for the following CCS elements will be computed at the baseline and 12 months: professional interactions (range 1-4), relationship initiation (range 1-5), exchange characteristics (role specification and trustworthiness; range 1-5), and commitment to collaboration (range 1-5). The Kruskal-Wallis test, Wilcoxon-signed rank test, or Analysis of Variance (ANOVA) test, as appropriate, will be used to assess the differences in CCS variables within and between different participant groups at baseline and 12 months [70,71]. Total scores for TES will be calculated for the participant groups. The differences in TES scores between participant groups will be assessed using Kruskal-Wallis or ANOVA test as appropriate [58,70]. The data will be analysed using Statistical Package for the Social Sciences (SPSS ver. 25 IBM, New York, NY, USA). 
Interview data will be coded and analysed independently by two investigators. Thematic analysis will be performed to analyse qualitative data [72]. The qualitative data analysis will utilise open and axial coding of transcripts [73]. The emerging themes will be reviewed by the research team with the aim of using the themes to explain the factors that describe interprofessional collaboration. Following the initial coding, a process of selective coding will be undertaken $[63,67]$. Thematic analysis will be performed with the assistance of NVivo qualitative data analysis software (ver. 12, QSR, Melbourne, VIC, Australia) [72]. Quantitative and qualitative results will be merged during interpretation to provide complementary perspectives of interprofessional collaboration.

\subsubsection{Outcomes}

The primary outcomes of this study are the level of team effectiveness and the changes in interprofessional collaboration over time, after a general practice pharmacist commences employment in general practices in the ACT. Using a longitudinal comparison between baseline and 12 months after including a pharmacist in general practice, the changes in professional interactions, exchange characteristics (relationship initiation, trustworthiness, and role specification) and commitment to collaboration will be identified. Competencies for interprofessional collaboration and facilitating and impeding factors for collaborative care will be identified by conducting semi-structured interviews.

\subsection{Part B-Interprofessional Collaboration and Team Effectiveness of General Practice Pharmacists in Australia, Canada, and the UK}

\subsubsection{Aims}

Part B aims to compare the level of interprofessional collaboration and team effectiveness in general practices in Australia with international sites (Canada and the UK), where the model of pharmacists working in general practice is more established $[28,30]$.

\subsubsection{Study Design}

A cross-national quantitative descriptive design (CCS and TES at one time point) will be utilised to compare the level of interprofessional collaboration and team effectiveness between Australia and Canada and the UK; and explore the demographic and contextual factors that influence interprofessional collaboration and team effectiveness of general practice pharmacists in Australia compared to Canada and the UK.

\subsubsection{Setting}

This study will be conducted in general practices in Australia where the inclusion of pharmacists into general practices has only recently expanded, and general practices in two countries, Canada and the UK, where the pharmacist in general practice model is relatively well developed [28,30]. General practices in Australia, Canada, and the UK include multiple health professionals to provide integrated care for patients.

\subsubsection{Participants and Recruitment}

A sample of general practice pharmacists from Australian states/territories, Canada, and the UK will be invited to participate in the online surveys. When calculating the sample size for a representative sample with a $95 \%$ confidence interval and $5 \%$ margin of error, 63 responses from Australia (total general practice pharmacists $n \approx 75$ [74], 323 responses from the UK (total general practice pharmacists $n \approx 2000$ ) [27] and 249 from Canada (total family practice pharmacists $n \approx 700$ [75]) will be required to adequately reflect the entire population of general practice pharmacists from Australia and the international sites [76]. Potential participants from Australian states/territories and the international sites will be identified through professional networks and contacts in relevant professional organisations already established by the investigators. The surveys will be advertised in newsletters and through networks of professional organisations. 


\subsubsection{Intervention}

General practice pharmacists are working together with general practitioners and other health professionals to provide integrated patient care as routine practice. This study does not include any additional intervention.

\subsubsection{Inclusion and Exclusion Criteria}

General practice pharmacists who are currently working in general practices in Australia, Canada, and the UK will be offered to participate in this study. General practice pharmacists described in Section 2.2.5 (i.e., involved in the ACT study) will be excluded from this study.

\subsubsection{Data Collection}

Quantitative data will be collected from general practice pharmacists in Australia and international sites through the CCS and TES online (Qualtrics, Provo, UT, USA) at one time point. These surveys will be available for six months for the participants.

\subsubsection{Data Analysis}

Descriptive statistics will be performed to summarise the demographic details of the participants. Total CCS and TES scores will be calculated for general practice pharmacists in Australia, Canada, and the UK. Spearman's or Pearson's correlation test will be performed to assess the relationship of professional interactions, relationship initiation, role specification, trustworthiness, team effectiveness, context characteristics, and individual characteristics, as appropriate. The Kruskal-Wallis or ANOVA test, as appropriate, will be performed to assess the differences in CCS variables between different countries [70]. Multiple linear regression will be performed to determine whether contextual and individual characteristics influence the total survey scores [37]. Collinearity will be assessed by computing the variance inflation factor.

\subsubsection{Outcomes}

In Part B of the study, the primary outcome will be the level of interprofessional collaboration and team effectiveness across general practices in Australia, where the practice pharmacist model is relatively new, compared to general practices in the UK and Canada, where the practice pharmacist model is more established. The secondary outcome will be identifying the factors that influence interprofessional collaboration in three different sites. The findings from this study will offer insight into the primary aspects of strengthening interprofessional collaboration and team effectiveness following the inclusion of pharmacists into general practice teams in Australia.

\subsection{Quality Control Measures}

Quality control measures will be followed in carrying-out research procedures and handling data. Microsoft Excel spreadsheets will be used for data entry and organisation. Data entries will be verified by two investigators to ensure the accuracy and to minimise errors when processing data [77]. If the cases with missing data are more than $5 \%$, multiple imputation will be performed to maximise the use of available information; and if the cases with missing data are less than $5 \%$, listwise deletion will be performed to minimise bias $[78,79]$.

\section{Ethics}

Ethical approval was obtained from the Human Research Ethics Committee of the University of Canberra (study protocol approval HREC 15-235).

\section{Data Management and Protection}

Anonymous data collected from health professionals in general practices will be stored electronically on a secure password-protected hard drive and transferred to a 
secure password-protected server. Access to the database will be by the key members of the research team with unique usernames and passwords. The servers are protected by firewalls and are maintained according to best practice. Hard copies of data (i.e., completed questionnaires and consent forms) will be stored in a secured filing cabinet in the university. Audio-recordings will be transcribed and stored electronically, and the original recording will be deleted; all transcripts will be completely anonymised. After the completion of the study and publication of the results, the data will remain on the university storage system for five years, as per National Health and Medical Research Council (NHMRC) guidelines [80].

\section{Discussion}

This study will explore the extent and factors that influence collaboration and team effectiveness in general practice teams following the introduction of pharmacists into general practices in Australia. There is limited quantitative data regarding interprofessional collaboration in general practices worldwide [81]. Gaining insights related to interprofessional collaboration and team effectiveness will be an essential step to enhance general practice pharmacists' services in Australia.

Furthermore, collaborative care and team effectiveness measures will be compared with comparator sites in Canada and the UK, where this practice model is more established $[28,30]$. The characteristics of the models of general practice pharmacists vary in these three sites. In the UK, the NHS has funded the inclusion of pharmacists in general practices, predominantly to reduce the general practitioners' workload and offer patients greater access to health services [26]. Furthermore, in the UK, general practice-based pharmacists have been offered independent and supplementary prescribing rights [82]. In Canada, the main focus of integrating pharmacists into primary care teams was to improve medication management through collaborative practice [24,29]. Like the UK, Canadian pharmacists in primary care teams can prescribe in some states/provinces [83].

In Australia, pharmacists are gradually being included in general practices to optimize patient health outcomes and support general practitioners to minimise medication-related problems [19]. The UK and Canada have been much more pro-active in the inclusion of pharmacists in patient care teams than in Australia. Australia lags behind in the inclusion of pharmacists into general practices due to health policy challenges and a lack of funding [64,84]. The functions and aims of general practice models in Australia, Canada, and the UK have shown similarities; however, regulations, remuneration, and implementation appear to be different [82-84].

\subsection{Strengths and Limitations}

A multiphase sequential explanatory mixed-method approach is the most suitable method to merge quantitative and qualitative findings during interpretation to provide complementary perspectives on inter-related contextual factors of interprofessional collaboration $[57,85]$. A mixed-methods approach prevents intrinsic biases that can arise in single method, single observer, and single theory studies [58,86]. Qualitative data analysis of the study will be performed by two researchers independently; this process ensures transparency in data coordination and interpretation [87]. The survey tools, which have been validated through previous studies, were modified for this study to apply to the general practice setting and pre-tested before being utilised in the study. Additionally, to improve the generalizability of findings, this study will compare the results across international sites as comparators where this integrated health care model is well established $[28,30,88]$. To our knowledge, this will be the first study to capture interprofessional collaboration and team effectiveness of general practice pharmacists in Australia compared to other countries.

There are limitations to the proposed study design. In Part A of the study, the small sample size and predetermined locations with the constrained availability of general practices employing a pharmacist are identified as limitations. However, a similar sample size has been utilised in prior studies to explore the general practice pharmacist 
model $[63,64,89]$. In the ACT, the recruited general practices may be more receptive to the inclusion of a general practice pharmacist into their team, and this may increase the risk of bias.

\subsection{Implications}

The quantitative and qualitative data obtained from this study will contribute to the paucity of literature in this area. Stakeholders and policymakers will benefit from the findings of the study through any recommendations to strengthen interprofessional collaboration and team effectiveness when integrating pharmacists into Australian general practices.

\subsection{Study Status}

To date, eight general practices in the ACT have been recruited by the CHN. All the general practices had recruited general practice pharmacists by March 2020. Quantitative and qualitative data collection has commenced in the ACT; quantitative data collection has commenced in Australia, Canada, and the UK.

Supplementary Materials: The following are available online at https:/ /www.mdpi.com/1660-460 1/18/3/966/s1, Additional file S1—CCS to assess interprofessional collaboration, Additional file S2-Team effectiveness survey, Additional file S3-Semi-structured interview guide

Author Contributions: Conceptualization, T.S., M.N., G.M.P., L.S.D. and S.K.; methodology, T.S., M.N., G.M.P., L.S.D. and S.K.; writing—original draft preparation, T.S.; writing—review and editing, T.S., M.N., G.M.P., L.S.D., J.T. and S.K.; supervision, S.K. and M.N.; funding acquisition, S.K., M.N., G.M.P., and L.S.D. All authors have read and agreed to the published version of the manuscript.

Funding: This research is partly funded by Capital Health Network (CHN): ACT's primary health network, grant number 25097479.

Institutional Review Board Statement: The study was approved by the Human Research Ethics Committee of the University of Canberra (study protocol approval HREC 15-235: 31-7-2020).

Informed Consent Statement: Informed consent will be obtained from all subjects involve in the study.

Data Availability Statement: Not applicable.

Acknowledgments: Katja Boom, Ravi Sharma, Barbara Gobis, Shane Jackson, Line Gunette, C. Freeman, Theo Niyosenga, and Iain Walker are greatly acknowledged for their enormous support.

Conflicts of Interest: The authors declare no conflict of interest. The funders had no role in the design of the study; in the collection, analyses, or interpretation of data; in the writing of the manuscript.

\section{References}

1. Swerissen, H.; Duckett, S.; Moran, G. Mapping Primary Care in Australia; Grattan Institute Report No. 2018-09; Grattan Institute: Melbourne, Australia, 2018. Available online: https://grattan.edu.au/wp-content/uploads/2018/07/906-Mapping-primarycare.pdf (accessed on 14 June 2019).

2. The Deloitte Access Economics Commissioned by Cornerstone Health. General Practitioner Workforce Report 2019; Cornerstone Health: Canberra, Australia, 2019. Available online: https://www2.deloitte.com/au/en/pages/economics/articles/generalpractitioner-workforce-report-2019.html (accessed on 6 August 2020).

3. The Deloitte Access Economics Commissioned by Australian Medical Association. Analysis of Non-Dispensing Pharmacists in General Practice Clinics; Deloitte Access Economics: Canberra, Australia, 2015. Available online: https://ama.com.au/system/ tdf / documents /DAE_Report.pdf?file=1\%26type=node\%26id=42083 (accessed on 17 July 2019).

4. McPake, B.; Mahal, A. Addressing the Needs of an Aging Population in the Health System: The Australian Case. Health Syst. Reform 2017, 3, 236-247. [CrossRef]

5. Australian Bureau of Statistics. National Health Survey_First Results 2017-18; ABS Cat No. 4364.0.55.001; Australian Bureau of Statistics: Canberra, Australia, 2018. Available online: https://www.abs.gov.au/statistics/health/health-conditions-and-risks/ national-health-survey-first-results / latest-release (accessed on 25 September 2019).

6. The Royal Australian College of General Practitioners. General Practice: Health of the Nation 2019; RACGP: East Melbourne, Australia, 2019. Available online: https:/ / www.racgp.org.au/FSDEDEV/media/documents/Special\%20events/Health-of-theNation-2019-Report.pdf (accessed on 25 September 2019). 
7. Health Workforce Australia. Australia's Future Health Workforce-Doctors; Department of Health: Canberra, Australia, 2014. Available online: https:/ / www1.health.gov.au/internet/main/publishing.nsf/content/F3F2910B39DF55FDCA257D9400786 2F9/\$File/AFHW\%20-\%20Doctors\%20report.pdf (accessed on 8 December 2019).

8. Duckett, S.; Swerissen, H.; Moran, G. Building Better Foundations for Primary Care; Grattan Institute Report No. 2017-06; Grattan Institute: Melbourne, Australia, 2017. Available online: https://grattan.edu.au/wp-content/uploads/2017/04/Building-betterfoundations-for-primary-care.pdf (accessed on 27 September 2020).

9. Tan, E.; Stewart, K.; Elliott, R.A.; George, J. An exploration of the role of pharmacists within general practice clinics: The protocol for the pharmacists in practice study (PIPS). BMC Health Serv. Res. 2012, 12, 246. [CrossRef] [PubMed]

10. Page, A.T.; Falster, M.O.; Litchfield, M.; Pearson, S.-A.; Etherton-Beer, C. Polypharmacy among older Australians, 2006-2017: A population-based study. Med. J. Aust. 2019, 211, 71-75. [CrossRef] [PubMed]

11. Schnipper, J.L.; Kirwin, J.L.; Cotugno, M.C.; Wahlstrom, S.A.; Brown, B.A.; Tarvin, E.; Kachalia, A.; Horng, M.; Roy, C.L.; McKean, S.C.; et al. Role of pharmacist counseling in preventing adverse drug events after hospitalization. Arch. Intern. Med. 2006, 166, 565-571. [CrossRef] [PubMed]

12. Uhl, M.C.; Muth, C.; Gerlach, F.M.; Schoch, G.G.; Müller, B.S. Patient-perceived barriers and facilitators to the implementation of a medication review in primary care: A qualitative thematic analysis. BMC Fam. Pract. 2018, 19, 3. [CrossRef] [PubMed]

13. Caughey, G.E.; Kalisch Ellett, L.M.; Goldstein, S.; Roughead, E.E. Suboptimal medication-related quality of care preceding hospitalisation of older patients. Med. J. Aust. 2015, 203, 220.e1-220.e2207. [CrossRef] [PubMed]

14. Pharmaceutical Society of Australia. Medicine Safety: Take Care; PSA: Canberra, Australia, 2019. Available online: https: / / www.psa.org.au/wp-content/uploads/2019/01/PSA-Medicine-Safety-Report.pdf (accessed on 6 July 2019).

15. Australian Institute of Health and Welfare. Hospital Resources 2016-17; Australian Hospital Statistics Cat. No. HSE 205; AIHW: Canberra, Australia, 2018. Available online: https:// www.aihw.gov.au/getmedia/c5fd554a-3356-474a-808a-5aab43d24708/aihwhse-205.pdf.aspx?inline=true (accessed on 27 September 2019).

16. Rigby, D. Collaboration between doctors and pharmacists in the community. Aust. Prescri. 2010, 33, 191-193. [CrossRef]

17. Bardet, J.D.; Vo, T.H.; Bedouch, P.; Allenet, B. Physicians and community pharmacists collaboration in primary care: A review of specific models. Res. Soc. Adm. Pharm. RSAP 2015, 11, 602-622. [CrossRef]

18. Tan, E.C.K.; Stewart, K.; Elliott, R.A.; George, J. Integration of pharmacists into general practice clinics in Australia: The views of general practitioners and pharmacists. Int. J. Pharm. Pract. 2014, 22, 28-37. [CrossRef]

19. Freeman, C.; Rigby, D.; Aloizos, J.; Williams, I. The practice pharmacist: A natural fit in the general practice team. Aust. Prescr. 2016, 39, 211-214. [CrossRef]

20. Tan, E.C.; Stewart, K.; Elliott, R.A.; George, J. Pharmacist consultations in general practice clinics: The Pharmacists in Practice Study (PIPS). Res. Soc. Adm. Pharm. RSAP 2014, 10, 623-632. [CrossRef] [PubMed]

21. Butterworth, J.; Sansom, A.; Sims, L.; Healey, M.; Kingsland, E.; Campbell, J. Pharmacists' perceptions of their emerging general practice roles in UK primary care: A qualitative interview study. Br. J. Gen. Pract. 2017, 67, e650-e658. [CrossRef] [PubMed]

22. Hazen, A.C.; Sloeserwij, V.M.; Zwart, D.L.; Zwart, D.L.M.; de Gier, J.J.; de Wit, N.J.; Leendertse, A.J.; Bouvy, M.L.; de Bont, A.A. Design of the POINT study: Pharmacotherapy Optimisation through Integration of a Non-dispensing pharmacist in a primary care Team (POINT). BMC Fam. Pract. 2015, 16, 76. [CrossRef] [PubMed]

23. Bradley, F.; Seston, E.; Mannall, C.; Cutts, C. Evolution of the general practice pharmacist's role in England: A longitudinal study. Br. J. Gen. Pract. 2018, 68, e727-e734. [CrossRef]

24. Dolovich, L.; Pottie, K.; Kaczorowski, J.; Farrell, B.; Austin, Z.; Rodriguez, C.; Gaebel, K.; Sellors, C. Integrating family medicine and pharmacy to advance primary care therapeutics. Clin. Pharmacol. Ther. 2008, 83, 913-917. [CrossRef]

25. Cardwell, K.; Clyne, B.; Moriarty, F.; Wallace, E.; Fahey, T.; Boland, F.; McCullagh, L.; Clarke, S.; Finnigan, K.; Daly, M.; et al. Supporting prescribing in Irish primary care: Protocol for a non-randomised pilot study of a general practice pharmacist (GPP) intervention to optimise prescribing in primary care. BMC Pilot Feasibility Stud. 2018, 4, 122. [CrossRef]

26. National Health Services England. Enhanced Service Specification-Clinical Pharmacists in General Practice Phase 2 Programme; NHS: London, UK, 2017. Available online: https:/ / www.england.nhs.uk/wp-content/uploads/2017/11/enhanced-service-clinicalpharmacists-gp.pdf (accessed on 15 December 2020).

27. The Pharmaceutical Journal. Pharmacists working in general practice increase by more than 40\% in one year. Pharm. J. 2019, 303. [CrossRef]

28. Dolovich, L. Ontario Pharmacists Practicing in Family Health Teams and the Patient-Centered Medical Home. Ann. Pharmacother 2012, 46, 33S-39S. [CrossRef]

29. Dolovich, L.; Austin, Z.; Waite, N.; Chang, F.; Farrell, B.; Grindrod, K.; Houle, S.; McCarthy, L.; MacCallum, L.; Sproule, B. Pharmacy in the 21st century: Enhancing the impact of the profession of pharmacy on people's lives in the context of health care trends, evidence and policies. Can. Pharm. J. 2018, 152, 45-53. [CrossRef]

30. Moles, R.J.; Stehlik, P. Pharmacy Practice in Australia. Can. J. Hosp. Pharm. 2015, 68, 418-426. [CrossRef]

31. Whitehead, P.A.; Sunderland, V.B.; Benrimoj, S.I. The 'general practice' pharmacist. Aust. J. Pharm. 2003, 84, $24-27$.

32. Australian Medical Association. General Practice Pharmacists_Improving Patient Care; AMA: Barton, Australia, 2015. Available online: https:/ / ama.com.au/article/general-practice-pharmacists-improving-patient-care (accessed on 14 December 2020).

33. Deeks, L.S.; Naunton, M.; Tay, G.H.; Peterson, G.M.; Kyle, G.; Davey, R.; Dawda, P.; Goss, J.; Cooper, G.M.; Porritt, J.; et al. What can pharmacists do in general practice? A pilot trial. AJGP Aust. J. Gen. Pract. 2018, 47, 545-549. [CrossRef] 
34. Freeman, C.; Cottrell, W.N.; Kyle, G.; Williams, I.; Nissen, L. Integrating a pharmacist into the general practice environment: Opinions of pharmacist's, general practitioner's, health care consumer's, and practice manager's. BMC Health Serv. Res. 2012, 12, 229. [CrossRef] [PubMed]

35. Benson, H.; Lucas, C.; Kmet, W.; Benrimoj, S.I.; Williams, K. Pharmacists in general practice: A focus on drug-related problems. Int. J. Clin. Pharm. 2018, 40, 566-572. [CrossRef] [PubMed]

36. Schot, E.; Tummers, L.; Noordegraaf, M. Working on working together. A systematic review on how healthcare professionals contribute to interprofessional collaboration. J. Interprof. Care 2020, 34, 332-342. [CrossRef]

37. Liu, Y.; Doucette, W.R.; Farris, K.B. Examining the development of pharmacist-physician collaboration over 3 months. Res. Soc. Adm. Pharm. 2010, 6, 324-333. [CrossRef]

38. International Pharmaceutical Federation. Good Pharmacy Practice: Joint FIP/WHO Guidelines; FIP: The Hague, The Netherlands, 2011. Available online: http://whqlibdoc.who.int/trs/WHO_TRS_961_eng.pdf (accessed on 16 December 2020).

39. Mickan, S.; Hoffman, S.; Nasmith, L. Collaborative practice in a global health context: Common themes from developed and developing countries. J. Interprof. Care 2010, 24, 492-502. [CrossRef]

40. Reeves, S.; Pelone, F.; Harrison, R.; Goldman, J.; Zwarenstein, M. Interprofessional collaboration to improve professional practice and healthcare outcomes. Cochrane Database Syst. Rev. 2017, 6, CD000072. [CrossRef]

41. O'connor, P.; O'dea, A.; Lydon, S.; Offiah, g.; Scott, J.; Flannery, A.; Lang, B.; Hoban, A.; Armstrong, C.; Byrne, D. A mixed-methods study of the causes and impact of poor teamwork between junior doctors and nurses. Int. J. Qual. Health Care 2016, 28, 339-345.

42. Stewart, M.A. Stuck in the middle: The impact of collaborative interprofessional communication on patient expectations. Shoulder Elb. 2017, 10, 66-72. [CrossRef]

43. McKinlay, E.; Gray, B.; Pullon, S. Interdisciplinary Collaboration: Working in Teams for Patient Care; Cole's Medical Practice in New Zealand; Medical Council of New Zealand: Wellington, New Zealand, 2013. Available online: https:/ /www.mcnz.org.nz/assets/ standards/da3a9995b9/Coles-Medical-Practice-in-New-Zealand.pdf (accessed on 2 December 2019).

44. O'Daniel, M.; Rosenstein, A.H. Professional Communication and Team Collaboration. In Patient Safety and Quality: An EvidenceBased Handbook for Nurses; Agency for Healthcare Research and Quality (US): Rockville, MD, USA, 2008; Chapter 33. Available online: https: / / www.ncbi.nlm.nih.gov /books/NBK2637/ (accessed on 16 June 2020).

45. Committee on the Science of Team Science; Board on Behavioral, Cognitive, and Sensory Sciences; Division of Behavioral and Social Sciences and Education; National Research Council. Overview of the Research on Team Effectiveness. In Enhancing the Effectiveness of Team Science; Cooke, N.J., Hilton, M.L., Eds.; National Academies Press (US): Washington, DC, USA, 2015. Available online: https: / / www.ncbi.nlm.nih.gov / books/NBK310387/ (accessed on 16 June 2020).

46. Babiker, A.; El Husseini, M.; Al Nemri, A.; Al Frayh, A.; Al Juryyan, N.; Faki, M.O.; Assiri, A.; Al Saadi, M.; Shaikh, F.; Al Zamil, F. Health care professional development: Working as a team to improve patient care. Sudan. J. Paediatr. 2014, 14, 9-16. [PubMed]

47. Rosen, M.A.; DiazGranados, D.; Dietz, A.S.; Benishek, L.E.; Thompson, D.; Pronovost, P.J.; Weaver, S.J. Teamwork in healthcare: Key discoveries enabling safer, high-quality care. Am. Psychol. 2018, 73, 433-450. [CrossRef]

48. Buljac-Samardzic, M.; Doekhie, K.D.J.; Van Wijngaarden, D.H. Interventions to improve team effectiveness within health care: A systematic review of the past decade. Hum. Resour. Health 2020, 18, 2. [CrossRef]

49. Mitchell, P.; Wynia, M.; Golden, R.; McNellis, B.; Okun, S.; Webb, C.E.; Rohrbach, V.; Von Kohorn, I. Core Principles E Values of Effective Team-Based Health Care; Discussion Paper; Institute of Medicine: Washington, DC, USA, 2012. Available online: https: //nam.edu/wp-content/uploads/2015/06/VSRT-Team-Based-Care-Principles-Values.pdf (accessed on 27 September 2020).

50. Gilbert, J.; Yan, J.; Hoffman, S.A. WHO report: Framework for action on interprofessional education and collaborative practice. J. Allied Health 2010, 39, 196-197. [PubMed]

51. Haj-Ali, W.; Moineddin, R.; Hutchison, B.; Wodchis, W.P.; Glazier, R.H. Physician group, physician and patient characteristics associated with joining interprofessional team-based primary care in Ontario, Canada. Health Policy 2020, 124, 743-750. [CrossRef]

52. Baird, B.; Reeve, H.; Ross, S.; Honeyman, M.; Nosa-Ehima, M.; Sahib, B.; Omojomolo, D. Innovative Models of General Practice; Kings Fund: London, UK, 2018. Available online: https://www.kingsfund.org.uk/sites/default/files/2018-06/Innovative_ models_GP_Kings_Fund_June_2018.pdf (accessed on 6 January 2021).

53. Freeman, C.; Cottrell, W.N.; Kyle, G.; Williams, I.; Nissen, L. Pharmacists', general practitioners' and consumers' views on integrating pharmacists into general practice. J. Pharm. Pract. Res. 2012, 42, 184-188. [CrossRef]

54. Jove, A.M.; Fernandez, A.; Hughes, C.E.A. Perceptions of collaboration between general practitioners and community pharmacists: Findings from a qualitative study based in Spain. J. Interprof. Care 2014, 28, 352-357. [CrossRef] [PubMed]

55. Schadewaldt, V.; McInnes, E.; Hiller, J.E.; Gardner, A. Experiences of nurse practitioners and medical practitioners working in collaborative practice models in primary healthcare in Australia-A multiple case study using mixed methods. BMC Fam. Pract. 2016, 17, 99. [CrossRef] [PubMed]

56. Van, C.; Costa, D.; Mitchell, B.; Abbott, P.; Krass, I. Development and validation of the GP frequency of interprofessional collaboration instrument (FICI-GP) in primary care. J. Interprof. Care 2012, 26, 297-304. [CrossRef]

57. Zillich, A.J.; Doucette, W.R.; Carter, B.L.; Kreiter, C.D. Development and initial validation of an instrument to measure physicianpharmacist collaboration from the physician perspective. Value Health 2005, 8, 59-66. [CrossRef] [PubMed]

58. Song, H.; Chien, A.T.; Fisher, J.; Martin, J.; Peters, A.S.; Hacker, K.; Rosenthal, M.B.; Singer, S.J. Development and validation of the primary care team dynamics survey. Health Serv. Res. 2015, 50, 897-921. [CrossRef] [PubMed] 
59. Creswell, J.W. Designing and Conducting Mixed Methods Research; Mixed Methods Research; Plano Clark, V.L., Ed.; SAGE Publications: Los Angeles, CA, USA, 2011.

60. Shorten, A.; Smith, J. Mixed methods research: Expanding the evidence base. Evid. Based Nurs. 2017, 20, 74. [CrossRef] [PubMed]

61. Pluye, P.; Bengoechea, E.G.; Granikov, V.; Kaur, N.; Tang, D.L. A World of Possibilities in Mixed Methods: Review of the Combinations of Strategies Used to Integrate Qualitative and Quantitative Phases, Results and Data. Int. J. Mult. Res. Approaches 2018, 10, 41-56. [CrossRef]

62. The Capital Health Network, CHN, ACT, Australia. Available online: https://www.chnact.org.au (accessed on 16 December 2020).

63. Deeks, L.S.; Kosari, S.; Naunton, M.; Cooper, G.; Porritt, J.; Davey, R.; Dawda, P.; Goss, J.; Kyle, G. Stakeholder perspectives about general practice pharmacists in the Australian Capital Territory: A qualitative pilot study. Aust. J. Prim. Health 2018, 24, 263-272. [CrossRef]

64. Tan, E.C.; Stewart, K.; Elliott, R.A.; George, J. Stakeholder experiences with general practice pharmacist services: A qualitative study. BMJ Open 2013, 3, e003214. [CrossRef]

65. Vasileiou, K.B.; Thorpe, J.; Young, S.T. Characterising and justifying sample size sufficiency in interview-based studies: Systematic analysis of qualitative health research over a 15-year period. BMC Med. Res. Methodol. 2018, 18, 148. [CrossRef]

66. Sutton, J.; Austin, Z. Qualitative Research: Data Collection, Analysis, and Management. CJHP Can. J. Hosp. Pharm. 2015, 68, 226-231. [CrossRef]

67. Ryan, K.; Patel, N.; Lau, W.M.; Abu-Elmgad, H.; Stretch, G.; Pinney, H. Pharmacists in general practice: A qualitative interview case study of stakeholders' experiences in a West London GP federation. BMC Health Serv. Res. 2018, 18, 234. [CrossRef]

68. Taber, K.S. The Use of Cronbach's Alpha When Developing and Reporting Research Instruments in Science Education. J. Res. Sci. Teach. 2018, 48, 1273-1296. [CrossRef]

69. Lindqvist, H.M.; Gustafsson, M.; Gallego, G. Exploring physicians, nurses and ward-based pharmacists working relationships in a Swedish inpatient setting: A mixed methods study. Int. J. Clin. Pharm. 2019, 41, 728-733. [CrossRef]

70. Harpe, S.E. How to analyze Likert and other rating scale data. CPTL Curr. Pharm. Teach. Learn. 2015, 7, 836-850. [CrossRef]

71. Savickas, V.; Foreman, E.; Ladva, A.; Bhamra, S.K.; Sharma, R.; Corlett, S.A. Pharmacy services and role development in UK general practice: A cross-sectional survey. IJPP Int. J. Pharm. Pract. 2020. [CrossRef] [PubMed]

72. Braun, V.; Clarke, V. Using thematic analysis in psychology. Qual. Res. 2006, 3, 77-101. [CrossRef]

73. Saldaña, J. The Coding Manual for Qualitative Researchers; SAGE Publications: London, UK, 2009. Available online: https:// stevescollection.weebly.com/uploads/1/3/8/6/13866629/saldana_2009_the-coding-manual-for-qualitative-researchers.pdf (accessed on 19 June 2020).

74. Freeman, C.; Associate professor/President, Pharmaceutical Society of Australia; Naunton, M.; Professor, Discipline of Pharmacy, University of Canberra, ACT, Australia. Personal communication, 2019.

75. The College of Family Physicians of Canada and the Canadian Pharmacists Association. Innovation in Primary Care: Integration of Pharmacists into Interprofessional Teams; College of Family Physicians of Canada and Canadian Pharmacists Association: Toronto, ON, Canada, 2019. Available online: https:/ / www.cfpc.ca/uploadedFiles/Health_Policy/IPC-2019-Pharmacist-Integration.pdf (accessed on 27 September 2020).

76. Qualtrics, X.M. Sample size calculator. In Academic Experience Sample Size Calculator; Qualtrics: Seattle, WA, USA, 2019. Available online: https:/ / www.qualtrics.com/blog/calculating-sample-size/ (accessed on 20 December 2019).

77. Jedinger, A.; Watteler, O.; Förster, A. Improving the Quality of Survey Data Documentation: A Total Survey Error Perspective. Data 2018, 3, 45. [CrossRef]

78. Jakobsen, J.C.; Gluud, C.; Wetterslev, J.; Winkel, P. When and how should multiple imputation be used for handling missing data in randomised clinical trials-A practical guide with flowcharts. BMC Med. Res. Methodol. 2017, 17, 162. [CrossRef]

79. Allison, P.D. Sage University Papers on Quantitative Applications in the Social Sciences, 07-136; Sage: Thousand Oaks, CA, USA, 2001.

80. National Health and Medical Research Council (NHMRC). Management of Data and Information in Research: A Guide Supporting the Australian Code for the Responsible Conduct of Research; NHMRC: Canberra, Australia; Australian Research Council: Canberra, Australia; Universities Australia: Canberra, Australia, 2019. Available online: https:/ /www.nhmrc.gov.au/about-us/publications / australian-code-responsible-conduct-research-2018\#download (accessed on 16 December 2020).

81. Supper, I.; Catala, O.; Lustman, M.; Chemla, C.; Bourgueil, Y.; Letrilliart, L. Interprofessional collaboration in primary health care: A review of facilitators and barriers perceived by involved actors. J. Public Health 2015, 37, 716-727. [CrossRef]

82. National Health Services England. Clinical Pharmacists; NHS: London, UK. Available online: https://www.england.nhs.uk/gp/ expanding-our-workforce/cp-gp/ (accessed on 16 December 2020).

83. Canadian Pharmacists Association. Pharmacists' Expanded Scope of Practice; CPhA: Ottawa, ON, Canada, 2020. Available online: https:/ / www.pharmacists.ca/cpha-ca/assets/File/pharmacy-in-canada/Scope\%20of\%20Practice\%20in\%20Canada_ June2020.pdf (accessed on 16 December 2020).

84. Calder, R.; Dunkin, R.; Rochford, C.; Nichols, T. Australian Health Services: Too Complex to Navigate. A Review of the National Reviews of Australia's Health Service Arrangements; Australian Health Policy Collaboration (AHPC) Policy Issues Paper No. 1; AHPC: Melbourne, Australia, 2019. Available online: https://apo.org.au/sites/default/files/resource-files/2019-02/apo-nid223011.pdf (accessed on 16 December 2020). 
85. Dowding, D. Best Practices for Mixed Methods Research in the Health Sciences John W. Creswell, Ann Carroll Klassen, Vicki L. Plano Clark, Katherine Clegg Smith for the Office of Behavioral and Social Sciences Research; Qualitative Methods Overview Jo Moriarty. Qual. Soc. Work 2013, 12, 541-545. [CrossRef]

86. Ivankova, N.V.; Creswell, J.W.; Stick, S.L. Using Mixed-Methods Sequential Explanatory Design: From Theory to Practice. Field Methods 2016, 18, 3-20. [CrossRef]

87. Leung, L. Validity, reliability, and generalizability in qualitative research. J. Fam. Med. Prim. Care 2015, 4, 324-327. [CrossRef]

88. Salkind, N.J. Encyclopedia of Research Design; SAGE Publications, Inc.: Thousand Oaks, CA, USA, 2010; Volume 1, pp. 1301-1314.

89. Benson, H.; Lucas, C.; Benrimoj, S.I.; Kmet, W.; Williams, K.A. Pharmacists in general practice: Recommendations resulting from team-based collaborative care. Aust. J. Prim. Health 2018, 24, 448-454. [CrossRef] 